\title{
Sobre a dicotomia língua e fala e os erros no processo de aquisição da linguagem
}

\author{
Irani Rodrigues Maldonade \\ Universidade Estadual de Campinas (UNICAMP), Campinas, São Paulo, Brasil \\ irani@fcm.unicamp.br
}

DOI: http://dx.doi.org/10.21165/el.v46i2.1696

\begin{abstract}
Resumo
O quadro de Saussure $(1972,2002)$ tem se mostrado importante referencial teórico para refletir sobre o processo de aquisição da linguagem, especialmente para pesquisadores interacionistas, que elegem o erro como dado privilegiado de análise. Desde a proposta de De Lemos (2002), enfrenta-se a necessidade de mostrar como a criança se encontra submetida à língua, em instâncias que possibilitam sua constituição como sujeito falante. $\mathrm{O}$ objetivo aqui é refletir sobre alguns erros no processo de aquisição da linguagem de crianças brasileiras, que dizem respeito à aquisição do léxico, levando-se em consideração a polêmica dicotomia entre língua e fala em Saussure. Este autor afirma que é ouvindo os outros que "aprendemos" a língua materna. Os erros aqui discutidos permitiram surpreender o pulsar da língua na fala da criança durante o processo de aquisição da linguagem; em outras palavras, no jogo ininterrupto da linguagem em funcionamento e seus efeitos, que ressaltam a indissociabilidade entre língua e fala.

Palavras-chave: aquisição da linguagem; erros na fala da criança; Saussure.

\section{About the language and speech dichotomy and errors in the language acquisition process}

\begin{abstract}
Saussure's framework $(1972,2002)$ has been pointed as an important theoretical reference to reflect about language acquisition process, especially for interactionist researchers, who elect the error as preferential data analysis. Since De Lemos (2002) proposal, there is a need to show how the children are submitted to language, in instances that enable their constitution as speaking subjects. The objective here is to reflect on some errors in Brazilian children speech, which concerns the lexical acquisition, taking into account the controversial dichotomy between language and speech in Saussure. This author affirms that it is listening to others that we "learn" the mother tongue. The errors discussed here allowed surprising the pulsation of language in the child's speech during the language acquisition process; in other words, in the language functioning uninterrupted game and its effects, which emphasize the indissociability between language and speech.
\end{abstract}

Keywords: language acquisition; errors in the child's speech; Saussure.

\section{Introdução}

No ano em que se comemora o centenário da primeira publicação do Curso de Linguística Geral (CLG), obra responsável pela fundação da Linguística enquanto ciência, pesquisadores do mundo todo se dedicam a avaliar a influência que as proposições de Saussure exercem para o avanço das áreas das ciências da linguagem. Sem dúvidas, a teorização interacionista desenvolvida por De Lemos desde 1982 e 
colaboradoras (CASTRO, 2010; FIGUEIRA, 1996, 2010, 2015) está entre elas, como este artigo pretende mostrar. Desde o início, essa perspectiva teórica sempre rejeitou a análise da fala da criança através das categorias oferecidas pelas descrições linguísticas. Além disso, recusa-se, até os dias de hoje, a tomar os enunciados das crianças como evidência de conhecimento categorial da língua. Ao invés disso, o diálogo é proposto como unidade de análise, de forma que a fala do outro é acolhida também como dado de análise, além da fala da criança. $O$ quadro teórico em questão afirma que a interação é a condição necessária para o processo de aquisição da linguagem, razão pela qual ele é chamado de interacionista.

Nas suas formulações teóricas, o esforço tem sido o de não deixar de lado nem o sujeito e nem a língua. Ao longo dessa teorização, os processos metafóricos e metonímicos propostos por De Lemos (1992) se mostraram como os adequados para demonstrar de que maneira as propriedades formais da linguagem (e da língua) podiam ser derivadas de processos de interação linguístico-discursivos. Desde então, a saída para descrever a fala da criança tem sido possibilitada pelo estruturalismo, enquanto programa teórico. A teorização interacionista conseguiu explicar que um passo fundamental para a constituição da criança como sujeito falante é a conversão da fala do outro em discurso próprio. É neste sentido que as polêmicas considerações feitas por Saussure em relação à dicotomia ente língua e fala tornam-se relevantes neste artigo, que tem como objetivo discutir alguns erros do processo de aquisição da linguagem de crianças brasileiras, que dizem respeito à aquisição do léxico, principalmente.

Para tanto, é antes necessário entender de que forma tem sido pensada a aproximação da teorização interacionista do quadro saussuriano; o que será apresentado, a seguir, na próxima seção.

\section{O quadro de Saussure e o interacionismo}

O quadro de Saussure $(1972,2002)$ tem se mostrado importante referencial teórico para analisar a fala de crianças em processo de aquisição da linguagem, principalmente para alguns investigadores interacionistas, que privilegiam o erro como dado de análise. Desde a proposta de De Lemos (2002), enfrenta-se a necessidade de mostrar como a criança se encontra submetida à língua, em instâncias que possibilitam sua constituição como sujeito falante. Cabe observar que:

Uma leitura de Saussure, motivada pelo problema da aquisição de linguagem, não é um ponto de partida evidente: o autor raras vezes traz para a sua reflexão a fala da criança e a infância não é para ele uma questão. Entretanto, essas duas noções se enlaçam no conceito de mudança - esse, sim, um tema saussuriano. (CASTRO, 2010, p. 91).

Conforme assinala Castro (2010), a aproximação do interacionismo ao quadro de Saussure fica viabilizada, principalmente, quando se busca refletir sobre a mudança linguística na fala da criança, em que o erro é, muitas vezes, protagonista.

Ao iniciar sua reflexão sobre a mudança, Saussure (2002) trata dos conceitos de fala e língua. Afirma que tudo na língua é história e, portanto, ela é um objeto de análise histórica e não de análise abstrata. Acrescenta ainda que a língua é composta de fatos e não de leis e que tudo o que parece orgânico na linguagem é, na realidade, contingente (os grifos são do autor) e completamente acidental. A história de toda língua é feita de 
sucessivos fatos linguísticos, que na maioria das vezes são completamente independentes entre si. O objeto que constitui a matéria da história representa, em certo sentido, atos humanos. Conclui o autor que os fatos linguísticos podem ser considerados como o resultado de atos individuais. Para Saussure, o ato linguístico tem a característica de ser o menos refletido, o menos premeditado, além de o mais impessoal.

Consequentemente, afirma que uma língua, considerada em duas datas distintas, não será jamais idêntica em si mesma. Define, com isso, o princípio da continuidade no tempo, em que se reconhece não haver na história da língua nenhum ponto de interrupção ou cessação, ruptura. Há, na língua, apenas transformação; o que definirá, para o genebrino, o princípio da mutabilidade. Segundo o autor, "não há, em lugar algum, reprodução ou produção de um ser linguístico novo, com existência distinta da que a precedeu" (SAUSSURE, 2002, p. 137). Com isso, refuta que ideias de hereditariedade e de reprodução das espécies possam ser validadas para o terreno da linguagem (e também para a aquisição da linguagem). Para ele, os dois princípios (continuidade e mutabilidade) são interdependentes, correlacionados. Assim, o autor toma o princípio da transformação como absoluto. Por isso, ele acredita que a essência dos fenômenos linguísticos sempre foi e sempre será a mesma; razão pela qual ele afirma que o problema da origem não é diferente do de suas transformações ou de suas condições permanentes, tal como está afirmado no Curso de Linguística Geral. Logo, não há porque esperar que os fenômenos linguísticos relativos à aquisição da linguagem sejam diferentes dos demais. Abre-se, portanto, para a teorização interacionista um caminho promissor para não só pensar a constituição do sujeito falante como explicar o processo de mudança linguística próprio da aquisição da linguagem. Em outras palavras, permite estreitar sua relação com a Linguística.

De fato, a teorização interacionista conclui que a mudança (linguística e subjetiva) é o aspecto essencial do processo de aquisição da linguagem. Esta é sinalizada pelo deslocamento da criança em diversas posições ${ }^{1}$ durante o processo de aquisição da linguagem. Normalmente, os estudos da área concentram-se apenas nas mudanças linguísticas, consideradas como construções cumulativas sobre a língua, aprendidas pelas crianças durante o processo de aquisição da linguagem, que é concebido como processo de aprendizagem. Optam pela Linguística da língua. Entretanto, todos os esforços na teorização interacionista têm sido realizados para não deixar de lado nem o sujeito nem a língua na explicação para o processo de aquisição da linguagem e optar pela Linguística da fala. Isso equivale a dizer que mudanças linguísticas implicam, ao mesmo tempo, mudanças subjetivas; mostradas muitas vezes através do erro na fala da criança, como em alguns exemplos que são comentados, a seguir, na próxima seção. De modo parecido, Arrivé (2010, p. 15) afirma que é preciso enfrentar o problema do lugar do discurso (ou o "jogo da linguagem no indivíduo") (aspas do autor) na reflexão saussuriana. Isso se torna fundamental, na visão do autor, dada a importância e relação do discurso com outras disciplinas. Por isso, procura demarcar as relações que se estabelecem entre fala, discurso e faculdade da linguagem.

\footnotetext{
${ }^{1}$ De Lemos (2002) deixa indicado que o processo de aquisição da linguagem é um processo de mudança linguística, que se caracteriza pelo deslocamento do sujeito em três diferentes posições: a primeira posição, em que se observa a prevalência da relação do sujeito com a fala do outro; a segunda, em que se verifica o sujeito preso ao movimento da língua; e a terceira posição, em que se observa, principalmente, a relação do sujeito com sua própria fala.
} 
Para dar continuidade à discussão proposta neste artigo, alguns erros na fala de crianças brasileiras durante o processo de aquisição da linguagem serão abordados na próxima seção.

\section{Discussão de alguns erros no processo de aquisição da linguagem}

Segundo Castro (2006), a teorização interacionista propõe uma visão estrutural da mudança como sendo o fenômeno capital da aquisição da linguagem. Isso acontece, de acordo com a autora, por conta de que o reconhecimento da ordem própria da língua, que é sustentado tanto por Saussure quanto por Chomsky, não pode ser defendido a partir de uma visão desenvolvimentalista em aquisição da linguagem, conforme proposto por De Lemos (2002). Sendo assim, esta autora rompe com a perspectiva desenvolvimentalista dominante na área, que trata a língua como um objeto estático bem-acabado e sustenta, coerentemente com a noção de autonomia da língua, a função desta como "captura".

Dessa forma, a partir do conceito de captura é que De Lemos (2002) define o fenômeno da mudança que ocorre no processo de aquisição da linguagem como "mudança de posição em uma estrutura". Ou seja, no percurso da criança de infans a sujeito falante ocorrem mudanças de posição da criança relativamente à fala do outro (chamada de primeira posição), à língua (chamada de segunda posição) e, consequentemente, à sua própria fala (chamada de terceira posição). E, desse percurso, os erros na fala da criança - dados privilegiados para análise - também fazem parte. É preciso deixar claro que eles estão presentes durante todo processo de aquisição da linguagem, embora apareçam de forma mais concentrada num dado momento (na segunda posição), na explosão do vocabulário da criança no processo de aquisição do léxico, conforme os exemplos 1, 2 e 3, abaixo, podem ilustrar. O modo como os termos língua e fala aparecem na teorização interacionista chamam a atenção. Por esta razão, pretendo deter-me, mais atentamente, a eles.

Esta pequena amostra de dados é composta pelas ocorrências de três sujeitos principais: crianças brasileiras, de 3 a 4 anos de idade, sendo que os dados de duas delas (M e AC) já subsidiaram trabalhos anteriores, tais como a dissertação de mestrado de Maldonade (1995), a tese de doutorado de Maldonade (2003) e outro, episodicamente agora acrescentado ao conjunto anterior. $\mathrm{Na}$ exposição, buscarei focar as formações que afetam a fala da criança, de modo a confirmar que o material linguístico analisado é capaz de validar a contribuição do pensamento saussuriano para a área de Aquisição da Linguagem.

A ocorrência 1, explorada em trabalho anterior ${ }^{2}$, focaliza o fenômeno analógico. Não seria absurdo reconhecer o significado deste termo também no processo de aquisição da linguagem, tendo em vista a alta frequência das inovações lexicais singulares no vocabulário infantil.

$$
3 ; 5.16\left(\mathrm{D}^{3}\right)
$$

\footnotetext{
${ }^{2}$ Maldonade (2015, p. 530-544), em artigo, versava sobre o conceito de analogia em Saussure (1972, 2002).

${ }^{3}$ Os números separados por ponto e vírgula, e depois por ponto, representam a idade da criança, AC na ocorrência em questão. Assim, 3;02.22 significa: três anos, dois meses e 22 dias. Se depois dos números ainda aparecer a letra $\mathrm{D}$, entre parênteses, indica que o dado foi registrado no diário (a outra fonte de dados existente). Caso contrário, ele é de gravação. As outras abreviaturas referem-se: a outra criança (M), à
} 
I: O que cê vai ser quando crescer?

AC: Bailarista, igal ca minha mãe.

I: Verdade?! Cê vai ter que se dedicar muito, viu!

AC: Minha mãe me leva junto na escola dela.

Não é impossível imaginarmos, na ocorrência acima, porque vias bailarista se tornou possível na fala da criança: ela se alinha a outras palavras que levam o sufixo ista, tais como: pianista, motorista, recepcionista. Embora a forma bailarista não exista no uso adulto da língua, ela está contemplada nas potencialidades combinatórias do português, como um "possível de língua".

Com relação a isso, é importante notar que implicados no conceito de analogia estão todos os demais que fundam o edifício teórico saussuriano: a noção de língua e fala, as relações sintagmáticas e associativas, a noção de sistema e valor, conforme Figueira (2015) aponta.

A próxima ocorrência, recolhida da fala de $\mathrm{M}$, ilustra como a analogia pode ser útil para analisar os itens lexicais criativos durante o processo de aquisição da linguagem.

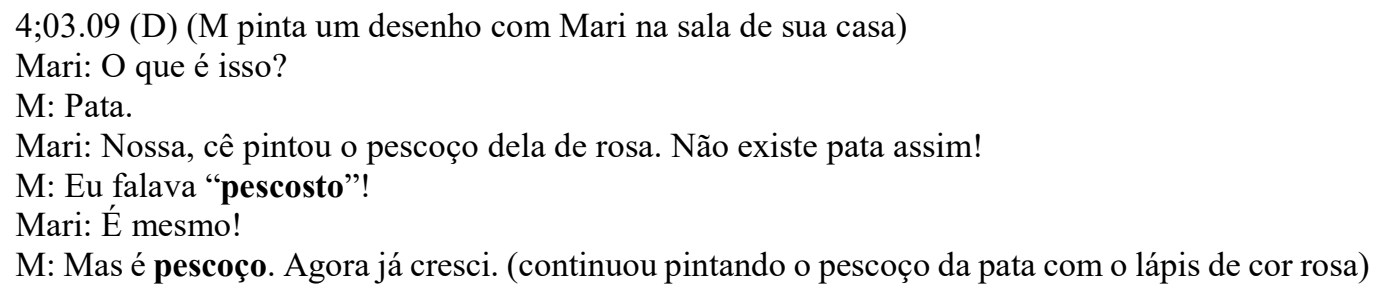

Pescoço, da fala de Mari, faz M lembrar-se de como esta pronunciava tal palavra. Fica realçado nesta ocorrência, de fato, um trabalho sofisticado da criança com a língua/linguagem, ao lembrar-se de sua posição anterior de falante no processo de aquisição da linguagem. O cálculo da quarta proporcional pode ser aplicado, sem entraves, para explicar por quais vias pescosto aparece na fala da criança: seu alinhamento a palavras como rosto e posto, por exemplo. Acrescenta-se a isso que, por um período de tempo, observou-se a fala de M capturada por um jogo fônico, na alternância (flutuação) entre palavras osso e caroço, em situações, tais como: "tira o caroço do frango" ou "olha o osso da uva". Deste modo, a ocorrência 2 mostra que a formação analógica pescosto pode ser interpretada como uma inovação lexical. Ela é seguida de uma autocorreção, quando $\mathrm{M}$, em seu próximo turno no diálogo, corrige sua fala anterior, ao dizer a forma esperada, pescoço. Não há como subtrair o fato de que duas formas são comparadas na fala da criança (pescoço e pescosto), produzindo como efeito uma mudança na relação da criança com a língua. Mostra-se, assim, a escuta que a criança já parece ter para a língua.

A ocorrência 3, a seguir, mostra outra situação dialógica em que a inovação lexical acontece na fala da criança, desta vez, na fala de $\mathrm{A}^{4}$, que pode ser explicada pelo conceito de analogia de Saussure (1972).

(3) 4;2.18 (D) A mãe de A derrama parte do leite com chocolate que pretendia colocar na caneca da criança, que observando o ocorrido disse:

A: Que burragem você fez, mamãe!

investigadora (I), à mãe de $\mathrm{M}(\mathrm{S})$, ao pai de $\mathrm{M}(\mathrm{L})$, à irmã mais velha de $\mathrm{M}$ (Dani), a outra irmã, também mais velha do que $\mathrm{M}$ (Mari) e à prima de $\mathrm{M}(\mathrm{A})$.

${ }^{4}$ Os poucos dados recolhidos da fala deste sujeito foram anotados em caderno diário. 


\section{I: Foi mais pra fora do que pra dentro.}

Limito-me, aqui, a apresentar apenas o episódio acima, mas deixo indicado que há muitos outros parecidos registrados na fala de A por volta dos quatro anos de idade. A relação (associação, de acordo com Saussure $(1972,2002)$ ) com a palavra bobagem (que está ausente), parece óbvia, nesta e nas demais ocorrências semelhantes a 3, em que burragem aparece. Também aqui o cálculo da quarta proporcional parece explicar o alinhamento entre as formas: se boba, bobagem; então burra, burragem.

Em relação à teorização interacionista e à analogia, Figueira $(2015$, p. 180) afirma que:

Para nós a noção de analogia, ou melhor, o que dela se retém como operação de mise en rapport, oferece a possibilidade de uma abordagem mais flexível, sem dúvida mais adequada para a posição do investigador que deseja se resguardar de analisar o processo com as categorias oferecidas (pela teoria linguística) para o produto - uma cautela que vigora para os interacionistas, a partir do texto inaugural de De Lemos (1982). Partindo de palavras alinhadas ou postas em relação no eixo associativo (in absentia) ou in presentia, e não de elementos menores (raízes e afixos), enquanto unidades previamente delimitadas, conta-se com um mecanismo de maior flexibilidade, apto a acolher tanto formações neológicas com certo grau de previsibilidade quanto aquelas que, para nossos ouvidos, soariam menos aceitáveis, por tomarem o caminho de aproximações/alinhamentos fora dos padrões esperados.

Para Saussure (1972), a analogia é de ordem psicológica e também gramatical. Ela supõe a compreensão de uma relação que une as formas entre si, que culmina com a proposição do cálculo da quarta proporcional: "se perdoar, imperdoável etc. $=$ decorar: $\mathrm{x}$, então x = indecorável” (v. SAUSSURE, 1972, p. 194). Entretanto, Maldonade (2015) apontou para a necessidade de a analogia estar inserida na teorização interacionista em aquisição da linguagem ou no "jogo da linguagem no indivíduo" (como diz ARRIVÉ, 2010), ou seja, dando lugar também à fala. Caso contrário, corre-se o risco de apenas explicar o erro ou a inovação lexical (forma analógica), ou seja, a língua na fala da criança de forma isolada, desconsiderando o processo de aquisição da linguagem em si, enquanto processo de subjetivação e de mudança linguística.

Com efeito, se as unidades vivas, sentidas pelos falantes, a um momento dado, podem por si sós dar origem a formações analógicas, reciprocamente toda repartição determinada de unidades supõe a possibilidade de o seu uso estender-se. A analogia é, pois, a prova peremptória de que um elemento formativo existe num momento dado como unidade significativa. (SAUSSURE, 1972, p. 198).

Os erros no processo de aquisição da linguagem dão prova disso. São formas flutuantes que, num tempo não tão distante no processo de aquisição da linguagem, serão suplantadas na fala das crianças pelas formas "corretas" (ou esperadas) de acordo com a língua adulta. E ao que parece, a analogia vista isoladamente pode ser insuficiente para explicar a entrada das formas esperadas na fala das crianças. Ela tem que estar integrada às relações paradigmáticas e sintagmáticas para poder incluir a fala do outro e a língua em movimento, num jogo de espelhamento e distanciamento da fala da criança. Caso contrário, a analogia não passará de um procedimento, de um cálculo, que só servirá para analisar estaticamente a língua como objeto num momento específico na fala da criança, sem conseguir explicar o processo de mudança linguística que constitui o processo de 
aquisição da linguagem. Além disso, não se deve esquecer que é pela fala que as mudanças entram na língua.

O pequeno conjunto de ocorrências apresentadas até agora são suficientes para responder de onde vieram as inovações lexicais mostradas nos erros da fala das crianças: da fala ou de formas, que estão na língua e pelas quais a nova formação singular passou, convocando relações no eixo associativo.

\section{Considerações}

Ao retomar o objetivo deste trabalho, depois de ter passado pela analogia, que expõe através da fala da criança uma relação indissociável entre língua e fala, cabe ressaltar que os capítulos 3 e 4 do CLG são, neste sentido, importantes e também estarrecedores, porque mostram de forma gradativa a angústia que representa entrar no terreno das definições de língua, fala e linguagem: "qualquer que seja o lado por que se aborda a questão, em nenhuma parte se nos oferece integral o objeto da Linguística".

Sempre encontramos dilemas: ou abordamos um lado apenas do problema ou nos arriscamos a não perceber as dualidades, ou, se estudarmos a Linguagem sob vários aspectos ao mesmo tempo, o objeto pode ficar obscuro. A solução apontada pelo CLG (1972) na página 16 é colocar-se primeiramente no terreno da língua e tomá-la como norma de todas as manifestações da linguagem. Mas para tanto, é necessário definir o que é língua. Eis o problema a ser enfrentado! A questão é trazida de volta à tona. De fato, as formas analógicas na fala das crianças mostram a necessidade de se dar lugar à fala, ou seja, ao acontecimento linguístico.

O fenômeno linguístico apresenta sempre duas faces que se correspondem e das quais uma não vale senão pela outra. As sílabas são impressões acústicas que chegam aos ouvidos, mas os sons não existiriam sem os órgãos vocais; assim um $n$ existe somente pela correspondência desses dois aspectos. A língua não pode ser reduzida ao som e não é o som que faz a linguagem. Ele não passa de instrumento do pensamento e não existe por si mesmo. O som, unidade complexa acústico-vocal, forma, por sua vez, com a ideia, uma unidade complexa, fisiológica e mental.

Para ilustrar o que está sendo afirmado, sirvo-me do episódio a seguir, flagrado em uma Unidade Básica de Saúde de uma cidade do interior paulista, em que atuo como supervisora de estágio.

(4) 1;06.12 (Uma criança dentro de um carrinho de bebê, empurrado por sua mãe, chega para o primeiro atendimento fonoaudiológico. A queixa apresentada pela mãe era de atraso de fala.)

Criança: Um (longo). Um (resmungo)

Mã! Mã! (criança olha para a mãe, balançando as pernas e esticando os braços em direção à mãe e emite esses sons)

Mãe: Você quer a mamãe? Quer o colinho da mamãe? (tom meigo)

Criança: Um, mã, mã, mã (a criança diminui o balançar das pernas, mantendo os braços esticados em direção à mãe, emitindo esses sons)

Mãe: Vem, vem, vem. Colinho gostoso da mamãe! (a mãe pega criança do carrinho, colocando-a em pé encostada em seu peito)

Criança: Ozumã. Mã (suspiro)

Mã, do enunciado da criança não é apenas um som. O fato é que as vocalizações da criança são interpretadas como linguagem quando incorporadas à fala da mãe que diz: 
"você quer a mamãe?", "Quer o colinho da mamãe?". A “fala" da criança é interpretada como um pedido. Após a fala da mãe, a criança diminui o balançar das pernas e permanece com seus braços esticados em direção à mãe. Ao final do episódio, o fragmento "ozumã", em que /o/ é colocado numa posição de tônica, pode ser interpretado como parte de "gostoso" e "mamãe", que migram da fala anterior da mãe para a da criança. Ozu e mãe são as sílabas de maior tonicidade no enunciado "colinho gostoso da mamãe" dito pela mãe.

Esses fragmentos denunciam que a criança faz movimentos em direção à língua e linguagem. Os sons da "fala" incipiente da criança são recobertos de sentido na fala da mãe. Mas essas vocalizações já poderiam ser consideradas como fala? Qual seria o limite para isso? O fato é que não se faz a mesma pergunta para a fala do adulto, em que a língua (já constituída) se apresenta. Com isso, pode-se perfeitamente entender porque os conceitos de língua e fala são propostos como interdependentes em Saussure.

Arrivé (2010) considera que o lugar atribuído à $f a l a^{5}$ por Saussure foi muitas vezes abordado (e até resolvido), sem que ao menos tivesse sido tratado. Refere-se, inicialmente, à posição já bastante conhecida entre linguistas, de que Saussure teria eliminado de seu projeto científico todas as considerações relativas às atividades do sujeito falante, ou seja, da fala e/ou discurso. Inúmeras passagens do CLG permitem comprovar isso, em que as definições de língua e fala são apresentadas dicotomicamente. Entretanto, duas passagens desses mesmos conceitos nos Escritos (SAUSSURE, 2002) expõem um ponto de vista que pode ajudar a compreender o pensamento de Saussure no que se refere à impossibilidade de separá-los. São elas: 1) "O mal-entendido em que caiu, de início, a escola fundada por [Franz] Bopp foi o de atribuir às línguas um corpo e uma existência imaginários exteriores aos indivíduos falantes" (SAUSSURE, 2002, p. 129) e 2) "A conquista desses últimos anos é a de ter, enfim, situado não apenas tudo o que é linguagem e a língua em sua verdadeira sede exclusivamente no sujeito falante, tanto como ser humano quanto como ser social" (SAUSSURE, 2002, p. 130).

Segundo Arrivé (2010), observa-se, então, a necessidade de enfrentar a "coexistência dos contrários", que é um fenômeno frequente na reflexão de Saussure. Engana-se completamente, diz o autor, quem percebe apenas uma das posições: a dicotomia entre língua e fala ou apenas a impossibilidade de tratá-los separadamente. Atualmente, vê-se que o conceito de fala de Saussure foi aproximado ao de discurso por vários autores. Afirma Bouquet (2000) que a última frase do CLG permitiria ver que Saussure conceberia a ciência da língua considerada em si mesma e por si mesma. Entretanto, o que se passa é exatamente o contrário: toda a dimensão social e intersubjetiva é, para Saussure, indissociável de uma "linguística da língua", segundo Bouquet (2000).

Arrivé (2010) propõe fazer uma análise que ele chamou de "lexical" dos termos língua/fala, discurso e faculdade da linguagem, iniciando pela leitura do quarto capítulo do CLG. Primeiramente, acredita que é preciso ler o título do capítulo com um novo olhar. Para interpretá-lo, é necessário levar em conta o sentido da definição da linguística feita no terceiro capítulo do CLG. Segundo o autor, dela decorrem duas consequências: a) que o sintagma "linguística da língua" é tautológico, pois apenas reafirma ser a língua o objeto da linguística e b) que o sintagma "linguística da fala" é oximoro, já que confere um objeto tido como impossível à linguística.

\footnotetext{
${ }^{5} \mathrm{O}$ autor adverte que conservará o termo fala, que se tornou tradicional pelo CLG.
} 


\section{Conclusão}

De acordo com o que foi exposto anteriormente, compreende-se o porquê de o título do quarto capítulo do CLG ter sido considerado provocador e escandaloso, na opinião de Arrivé (2010). Saussure (1972) adverte que, ao lado da linguística da língua, há também a linguística da fala. Pode-se concluir, portanto, que a fala não é concebida no CLG como impossível. Ao contrário, ela é parte legítima e indispensável da linguística da língua, como os dados da fala de crianças em processo de aquisição da linguagem puderam mostrar. Língua e fala são dois objetos interdependentes. Mais do que isso, os erros no processo de aquisição da linguagem foram suficientes para mostrar que a língua é, ao mesmo tempo, instrumento e produto da fala, conforme é anunciado por Saussure (1972) no CLG. Acontece que para haver fala é preciso que haja língua. Por isso tornase legítimo indagar: o que seria uma fala sem língua? Vocalizações? Mesmo assim, estas poderiam estar inseridas no terreno da linguagem, como a ocorrência 4 pôde mostrar. Mas o que é uma fala sem que seja possível identificar (nela) uma língua? Esta é uma questão que qualquer pesquisador da área de Aquisição da linguagem (ou fonoaudiólogo) tem logo que lidar ao descrever o início do processo de aquisição da linguagem de qualquer criança, em que a língua ainda está por se constituir. É fato que antes mesmo de falar, a criança significa. Emite sons que aos poucos vão ganhando o contorno (caminho) da língua à qual a criança está imersa. Paulatinamente, a língua parece pulsar na fala das crianças durante o processo de aquisição da linguagem, conforme registrado pela ocorrência 4.

Em relação à dicotomia língua e fala no CLG, Arrivé (2010) discorda de Bouquet (2000), ao afirmar que o termo discurso é censurado nessa obra. Além disso, afirma-se que "as relações associativas se situam fora do discurso" (ARRIVÉ, 2010, p. 170). Para Arrivé (2010), o termo discurso, nesta passagem, significa "produto do ato de fala". O autor defende que, às vezes, ele é usado para designar o ato de fala propriamente dito.

De sua análise lexical, Arrivé (2010) conclui que a consideração do sujeito falante não está ausente do CLG. Alega que os conceitos estão lá, sob a tripla forma da fala: como objeto da linguística, do discurso e da faculdade da linguagem.

O último termo é o menos favorecido no CLG. Tem-se que "a língua é um produto social da faculdade da linguagem.". Isso é verdade, mas corresponde a um dos dois aspectos da faculdade da linguagem, segundo Arrivé (2010). O outro é que "a língua é produto social cuja existência permite ao indivíduo exercer a faculdade da linguagem" (apud KOMATSU, 1993, p. 276). Logo, "não é a linguagem que é natural ao homem, mas a faculdade de constituir uma língua" (SAUSSURE, 1972, p. 18).

Já o termo fala nos Escritos (SAUSSURE, 2002) é recoberto por três sentidos diferentes: 1) como "fonação", 2) como "ato consciente e intencional de encadeamento de unidades em uma sequência efetivamente realizada" (correspondendo à sintagmação de Benveniste, que chama de sintagma a fala efetiva - ou o regime no qual os elementos se encontram ligados entre si por sua sequência e precedência (SAUSSURE, 2002, p. 61) e 3) como ato de fala e exercício da fala, ao mesmo tempo.

Dessa forma, conclui Arrivé (2010, p. 122) que a polissemia do termo fala é, sem dúvidas, uma das causas da marginalização de que ele foi vítima por parte dos editores de 1916: 
[...] talvez eles tenham encarado o termo no sentido de "fonação", algo legítimo e, pelo menos, compreensível, de fazer, dado que ele é quase sempre portador desse sentido no texto saussuriano. Continua o autor: "Por isso é que eles tinham uma boa razão para se verem tentados a excluí-lo do campo da linguística: Saussure já fazia esse gesto ao excluir a "fonologia", no sentido de descrição da fonação, do campo linguístico.

Observa o autor que o termo discurso também é polissêmico em Saussure, mas este não oscila de sentido tanto quanto a fala. No CLG, às vezes ele toma o sentido de fala para designar o produto da atividade do sujeito falante. Arrivé (2010) discorda também que se possa tomar a faculdade da linguagem como sinônimo para fala. Para ele, a faculdade da linguagem é mais extensiva do que a fala. Ela engloba os atos de fala para os quais a língua, estabelecida como instituição social, abre caminho, assim como abarca o processo de constituição da língua. Para Castro (2015, p. 92), Saussure expressa dramaticamente a passagem da língua para o discurso nos Escritos de Linguística Geral (2002), quando afirma que a língua só existe em função do discurso e se pergunta sobre o que separa o discurso da língua ou ainda "o que, em dado momento, permite dizer que a língua entra em ação como discurso".

Arrivé (2010, p. 127) afirma que não há dúvidas de que a linguística da fala relaciona-se ao projeto de uma linguística do discurso (ou do jogo da linguagem no indivíduo). Observa o autor que uma terminologia é proposta. Nem sempre perfeita, pois a ambiguidade e a polissemia estão sempre presentes no projeto científico de Saussure. Porém, segundo o autor, esses fenômenos estão ligados aos próprios conceitos que os termos pretendem significar.

"Em suma, tudo está pronto para o desenvolvimento de uma linguística saussuriana do "jogo da linguagem no indivíduo", desembaraçada das modalizações pejorativas e desagradáveis que afetam o projeto de "linguística da fala"" (ARRIVÉ, 2010, p. 127). É neste sentido que a proposta interacionista de aquisição da linguagem faz a sua aposta, concebendo a indissociabilidade entre lingua e fala e marcando, decisivamente, a influência de Saussure nessa teorização. A fala da criança e o próprio conceito de língua são colocados em questão no campo da aquisição de linguagem que tem o compromisso de explicar a passagem de infans a sujeito falante.

\section{REFERÊNCIAS}

ARRIVÉ, M. Em busca de Ferdinand de Saussure. Tradução de M. Marcionilo. São Paulo: Parábola Editorial, 2010.

BOUQUET, S. Introdução à Leitura de Saussure. São Paulo: Cultrix. 2000.

CASTRO. M. F. P. Sobre o (im)possível esquecimento da língua materna. In: LIER-DEVITTO, M. F.; ARANTES, L. (Org.). Aquisição, Patologias e Clínica de linguagem. São Paulo: Editora PUC-SP EDUC, 2006. p. 135-148.

Saussure e o necessário esquecimento da fala infantil: uma leitura para a aquisição de linguagem. Cadernos de Estudos Linguísticos, Campinas, v. 52, n. 1, p. 91$102,2010$.

DE LEMOS, C. G. Sobre a aquisição da linguagem e seu dilema (pecado) original. Boletim da Abralin, n. 3, p. 97-126, 1982. 
- Los processos metafóricos y metonímicos como mecanismo de cambio. Substratum, n. 1, p. 121-135, 1992.

. Das vicissitudes da fala da criança e de sua investigação. Cadernos de Estudos Linguísticos, Campinas, n. 42, p. 41-69, 2002.

FIGUEIRA, R. A. O erro como dado de eleição nos estudos de aquisição da linguagem. In: CASTRO, M. F. C. (Org.). O método e o dado no estudo da linguagem. Campinas: Editora da UNICAMP, 1996. p. 55-86.

. O que a investigação sobre o erro na fala da criança deve a Saussure. Cadernos de Estudos Linguísticos, Campinas, v. 52, n. 1, p. 115-143, 2010.

Em torno da analogia: a contribuição de Saussure para a análise da fala da criança. Pró-língua, João Pessoa, v. 10, n. 1, p. 174-189, 2015.

KOMATSU, E. Ferdinand de Saussure - Cours de linguistique générale. Premier et troisième cours d'après les notes de Riedlinger et Constantin. Tokyo: Université Gakushuin, 1993.

MALDONADE, I. R. Erros na aquisição de verbos com alternância vocálica: uma análise sócio-interacionista. 1995. 211 f. Dissertação (Mestrado em Linguística) Instituto de Estudos da Linguagem, Universidade Estadual de Campinas, Campinas, 1995.

. Erros na aquisição da flexão verbal: uma análise interacionista. $2003.167 \mathrm{f}$. Tese (Doutorado em Linguística) - Instituto de Estudos da Linguagem, Universidade Estadual de Campinas, Campinas, 2003.

. O erro e a autocorreção na relação da criança com a língua. Estudos Linguísticos, São Paulo, v. 41, n. 2, p. 403-418, 2012.

. Instâncias da língua na fala da criança. Estudos Linguísticos, São Paulo, v. 43, p. 666-678, 2014.

Sobre a analogia e os erros no processo de aquisição da linguagem. Estudos Linguísticos, São Paulo, v. 44, n. 2, p. 530-544, 2015.

SAUSSURE, F. Curso de Linguística Geral. São Paulo: Cultrix, 1972.

Escritos de Linguística Geral. Organizado e editado por Simon Bouquet e Rudolf Engler. São Paulo: Cultrix, 2002.

Recebido em: 31/08/2016

Aprovado em: 03/05/2017 